\title{
КУЛЬТУРНАЯ ПОЛИТИКА В РОССИЙСКИХ РЕГИОНАХ: КОРЕННЫЕ НАРОДЫ, ГОСУДАРСТВО И КОРПОРАЦИИ
}

\begin{abstract}
В статье на основе полуструктурированных интервью, анализа документов и наблюдения анализируются роли корпораций в производстве культурной политики в российских регионах. Рассматриваются различные подходы к пониманию государственной культурной политики и функции, которые могут выполнять негосударственные акторы в процессе ее формирования. Основное внимание уделяется корпоративным проектам в сфере сохранения и развития культуры коренных народов Севера и Дальнего Востока. Выбранные для исследования регионы характеризуются высокой социально-экономической зависимостью от присутствия добывающих корпораций. Несмотря на инновационный потенциал частных акторов, описываемый в теоретической литературе, в российских регионах корпоративные проекты дублируют государственную политику в этой сфере и воспроизводят традиционалистский подход. Большинство проектов, поддержанных нефтегазовыми корпорациями, связаны с реконструкцией традиционных праздников и ремесел и нацелены на фольклоризацию традиционных знаний, что ведет к консервации сложившихся культурных паттернов и поддержанию условного традиционализма. Приверженность традиции рассматривается участниками не только как способ повышения символической значимости культуры, но и как инструмент, позволяющий реализовывать прикладные задачи, связанные с решением повседневных проблем. На основе проведенного исследования показано, что сохранению зачастую подлежит «традиционная культура» коренных народов,
\end{abstract}

Наталья Геннадьевна Жидкова- к.полит.н., доцент, Северо-западный институт управления, Российская академия народного хозяйства и государственной службы, Санкт-Петербург, Россия. Электронная почта: zhidkova.ng@gmail.com

Светлана Александровна Тулаева- к.с.н., PhD in Legislative studies, доцент, Северо-западный институт управления, Российская академия народного хозяйства и государственной службы, Санкт-Петербург, Россия. Электронная почта: svett07@mail.ru 
фактически сконструированная в советское время в процессе «окультуривания» и гомогенизации. Основные факторы, нейтрализовавшие креативный потенциал негосударственных акторов, связаны с инструментализацией культуры, при которой культурная политика рассматривается в контексте достижения целей несвязанных со сферой искусства. Инструментализация культурной политики осуществляется как государственными, так и негосударственными акторами с сохранением патерналистского отношения между корпорациями и местными сообществами. В статье предпринята попытка реконструкции ожиданий государства и корпораций в отношении культуры коренных народов, которым местные жители вынуждены соответствовать.

Ключевые слова: государственная культурная политика, нефтегазовые корпорации, коренные народы, Север России, Дальний Восток

DOI: 10.17323/727-0634-2020-18-3-429-444

Культурная политика является предметом общественной дискуссии: культурные события входят в политическую повестку через события как политического, так и неполитического поля: судебные разбирательства вокруг организаций в сфере культуры, конфликты вокруг содержания художественных произведений разной направленности. Это отражает проблемы политики культуры, выраженные в вопросах кто, как и на каких основаниях распределяет государственные средства на культуру. Эти проблемы актуализируются на фоне неблагоприятной экономической конъюнктуры и недостатка средств. Необходимость поиска негосударственных инвестиций в сфере культуры отражена, например, в нормативных документах (Правительство РФ 2016: п.2). Один из вариантов оптимизации финансовых и организационных ресурсов связан с расширением присутствия в поле культуры негосударственных игроков, например коммерческих организаций.

Негосударственные акторы могут быть успешны в создании культурных проектов, которые соответствуют запросам современного общества и позволяют делать вклад в экономический рост (Gurova 2020; Abankina 2016; Menger 2010). Речь идет не только о разных вариантах частных инвестиций в культурные проекты, но и о привлечении негосударственных акторов к реализации государственной культурной политики. Так, в ряде регионов, где работают крупные ресурсодобывающие корпорации, обладающие значительными финансовыми и организационными активами, негосударственные акторы формируют собственную культурную повестку (Rodgers $2015)$ и предлагают альтернативу государственной культурной политике. Как соотносятся стратегии государственных и негосударственных акторов в процессе реализации культурной политики? Меняют ли негосударственные игроки общий тренд культурной политики в регионе?

Поиску возможностей и границ влияния негосударственных акторов в сфере культуры на примере регионов проживания коренных малочисленных 
народов Севера, Сибири, Дальнего Востока (КМНС) посвящена эта статья. Для понимания соотношения корпоративной и государственной культурной политики в отношении КМНС используется междисциплинарный подход, сочетающий элементы политологического анализа и социальной антропологии. Анализ государственных программ федерального и регионального уровня в сопоставлении с корпоративными проектами по сохранению и развитию культуры КМНС позволяет описать декларируемую культурную повестку государственных и негосударственных акторов. Культурная политика рассматривается как политически слабое направление, что позволяет навязывать потребности и интересы как государственных, так и негосударственных акторов в этой сфере (Hadley, Gray 2017). Поэтому для исследования недостаточно концентрироваться только на эксплицитной политике. Не менее важно рассмотреть, как воспринимаются формы культурных проектов, поддерживаемых государством и корпорациями, самими реципиентами. Авторы реконструируют культурные паттерны, воспроизводимые КМНС и поощряемые государством и корпорациями.

\section{Методология исследования}

Работа сфокусирована на анализе взаимодействия государственных структур, нефтегазовых компаний и коренных народов в сфере реализации культурных программ и мероприятий. Исследование проведено на территории Ненецкого АО (НАO), Ханты-Мансийского АО (ХМАO), Сахалинской области и Ямало-Ненецкого АО (ЯНАО). Здесь функционируют такие крупные нефтегазовые компании как «Лукойл», «Роснефть», «Сахалинская энергия», «Эксон», «Сургутнефтегаз», «Газпром», «НОВАТЭК». Они поддерживают развитие социальной инфраструктуры в этих округах: строят и ремонтируют школы, дома культуры, спортзалы, прокладывают дороги. В сферу их социальной ответственности входит сохранение и развитие культуры коренных народов. На территории этих округов проживает значительное число представителей коренных малочисленных народов. В НАО и ЯНАО проживают ненцы, ханты, селькупы, в ХМАО - ненцы, ханты и манси, на Сахалине - нивхи, ульта, эвенки, нанайцы.

Для изучения роли предприятий в сохранении и развитии культуры КМНС проведено 50 полуструктурированных интервью с представителями коренных народов, работниками государственных организаций в сфере культуры и образования, представителями областных и местных органов власти, нефтегазовых компаний, экспертами НКО по правам коренных народов. Из них 30 интервью собрано с представителями коренных народов ${ }^{1}$. Выборка осуществлялась методом «снежного кома». Интервью анализировались с применением тематического осевого и выборочного

\footnotetext{
${ }^{1}$ Список информантов предоставляется авторами по запросу.
} 
кодирования. Также рассмотрены федеральные и региональные программы культурной политики; материалы региональных СМИ; корпоративные и региональные программы поддержки коренных народов и корпоративные проекты, связанные с поддержанием культуры коренных народов («Лукойл», «Роснефть», «Сахалинская энергия», «Эксон», «Сургутнефтегаз», «Газпром», «НОВАТЭК»). В работе использованы материалы наблюдений, собранные на конференциях, обучающих семинарах и в поселениях коренных жителей. Информация, полученная в интервью, соотносилась с данными из документов и при наблюдении.

\section{Государственная}

\section{культурная политика и коренные народы}

Современные исследования выделяют четыре основных измерения культурной повестки: культура как искусство, культура как часть экономики, культура как основа для инноваций и культура как инструмент выстраивания этнической идентичности (Gurova 2020; Dubois 2013; Menger 2010; Mulcahy 2006; McGuigan 2004). Конфигурация данных измерений представляет собой модель культурной политики, доминирующей в тот или иной исторический период.

Особенность советской культурной политики связана с более ранним, чем в Западной Европе, формированием «демократизации культуры», означающей равный доступ граждан к культурным благам (Menger 2010). Равный доступ оказался возможным только при интенсивном вмешательстве государства в регулирование сферы культуры. В Западной Европе такое вмешательство стало заметным в послевоенное время (McGuigan 2004), в то время как советское государство контролировало сферу культуры и обеспечивало равенство доступа к культурным благам с самого начала своего существования (Чуйкина 2005). Театры, клубы, библиотеки, живопись, народное творчество стали инструментом формирования новой советской идентичности в процессе «окультуривания» (Хестанов 2013; Лебина 1999; Волков 1996). Последнее подразумевало гомогенизацию национальной идентичности. В рамках этой стратегии потребители культуры априори рассматривались как «бескультурные», необразованные и непросвещенные, соответственно главная политическая задача состояла в том, чтобы поднять культурный уровень граждан до условно нормативного советского человека.

Советская культурная политика в отношении коренных народов Севера следовала общему направлению. Для нее характерны стигматизация традиционного образа жизни КМНС и ориентация на его ускоренную модернизацию (Новикова 2013). В концепцию модернизации включалось распространение общего стандартизированного школьного образования и создание письменности для тех народов, которые ее не имели. Отдельные 
элементы культуры сохранялись через создание краеведческих музеев и домов культуры, а идеологически неугодные элементы (например языческие верования) подвергались стигматизации. Так, местные шаманы, являвшиеся лидерами сообществ, отправлены в лагеря. Детей изолировали в интернатах, чтобы дать им советское образование, непригодное для традиционного образа жизни. Вместо родовых общин, являвшихся основной формой организации местного населения, создавались колхозы.

Все это вело к сильной трансформации социальных норм и привычного образа жизни. В наших интервью одна из старожилов поселка нивхов рассказывала о том, как происходила ломка традиционных норм в 1930-е гг. на Сахалине. Для нивхов характерно уважительное и трепетное отношение к земле, считавшейся священной,- ей нельзя было «причинять боль», втыкать нож или другие острые предметы. В годы советской власти нивхов начали заставлять вступать в колхозы и обрабатывать землю. Проводимая советской властью модернизация и «перекраивание» культуры коренных народов по советским лекалам были очень болезненными. С точки зрения культурных традиций отказ от прежних норм и ценностей, совершаемые «преступные действия» требовали ритуального жертвоприношения и искупления:

Комиссар выстроил всех в ряд, выдал лопаты и сказал копать землю. А это ведь нельзя было делать. Земля, она же священная для нас была. Он на них кричит, а с места никто не двигается. Тогда моя мама решилась первой это сделать. Но прежде, чем воткнуть в землю лопату, она отрубила себе мизинец и проглотила его. И только после этого смогла воткнуть лопату в землю (представитель коренного населения-1, дер. В, 2015).

Советская культурная политика в отношении коренных народов характеризовалась целым рядом противоречий и парадоксов. С одной стороны, советская власть прилагала усилия для дальнейшего развития культуры коренных жителей: создавала письменность, организовывала в поселках школы, библиотеки, дома культуры. С другой стороны, модернизация проводилась репрессивными методами, без учета культурных особенностей и потребностей самих народностей. Советская власть осуществляла поиск усредненного образа жителя далекого Севера и под этот стереотип подгонялось все культурное многообразие. Брюс Грант отмечает, что советская политика привела к формированию новых этносов. Так, нивхская культура, дошедшая до наших дней-в основном изобретение советской власти (Grant 1995: 110-117).

Новые изменения политики в отношении коренных народов принесли 1990-е годы, чему немало способствовали международные тенденции. В стандартах, продвигаемых $\mathrm{OOH}$, Всемирным банком и другими организациями, обращается особое внимание на проблемы коренных народов и необходимость сохранения их самобытной культуры (Новикова 2013; Stammler, Wilson 2006). Международные фонды и организации, защищающие 
права коренных народов, способствовали развитию российского движения КМНС. Принят ряд законов, гарантирующих права коренных народов на сохранение своего традиционного образа жизни (Федеральный закон 1999а; 2001). В северных регионах началась реконструкция национальной культуры, связанная с попытками восстановления утерянного. Государство стало активно формировать «традиционность», поддерживая и субсидируя все, что можно маркировать как «традиция». В государственных документах федерального уровня обращение к традиционности означало сохранение языка, культурного наследия досоветского периода и традиционных видов хозяйственной деятельности (Правительство РФ 2009).

В настоящее время на федеральном уровне культурная политика в отношении КМНС регулируется комплексом нормативных документов. В законе о культуре прописан «протекционизм (покровительство) в отношении сохранения и восстановления культурно-национальной самобытности малочисленных этнических общностей» (Федеральный закон 1992: ст. 22). Речь идет о сохранении наследия или же о модернизации культурной инфраструктуры, о формировании мобильных учреждений культуры (см.: Президент РФ 2013: ст. 10). Рассматриваемые регионы руководствуются в политике специальными законами, в которых закрепляется право местных властей создавать условия для сохранения и возрождения наследия и оказывать поддержку регионам «традиционного художественного промысла» (Федеральный закон 1999b: ст. 4). В целом в региональных государственных программах просматривается несколько направлений культурной деятельности: (1) поддержка специальных мероприятий (Администрация НАО 2013); (2) сохранение и распространение культурных ценностей КМНС (Правительство ХМАОЮГРЫ 2013; Правительство ЯНАО 2013); (3) сохранение традиционного образа жизни, поддержка традиционной хозяйственной деятельности (Правительство НАО 2019; Правительство ЯНАО 2016). Анализ нормативной базы позволяет сделать вывод, что государственная политика нацелена на консервацию сложившихся культурных паттернов. Даже когда речь идет о развитии традиционной хозяйственной деятельности (например оленеводства), последняя рассматривается прежде всего с позиции ценности сохранения традиционной культуры, нежели ее экономической значимости и дальнейшего включения в рыночные отношения. В то же время культура малых народов не рассматривается как основа для стимулирования инноваций, дальнейшего развития сообществ в условиях рыночного контекста. Культурная сфера в законах регионального уровня закрепляется как сохранение материального и нематериального традиционного наследия. Появление в северных регионах новых влиятельных игроков в лице нефтегазовых корпораций, позволило государству переложить на них часть своих социальных функций, в том числе связанных с поддержкой КМНС. 


\section{Корпоративные проекты по сохранению и развитию культуры коренных народов}

Корпорации, ориентирующиеся на международные стандарты (United Nations 2009; EBRD 2014), требующие уважения к культурам коренных народов, а также под давлением органов власти, ожидающих корпоративных инвестиций в социальную инфраструктуру регионов, стали активно участвовать в проектах по сохранению их культуры. Это позволило корпорациям поддерживать имидж социально-ответственных игроков, претендовать на получение кредитов в международных финансовых институтах, а также устанавливать хорошие отношения с региональными и районными властями (Novikova, Wilson 2013). Нефтегазовые корпорации как ключевые агенты, принимающие решения о грантовой поддержке культурных промыслов, хозяйственных или инфраструктурных проектов, существенно влияют на выбор направлений развития коренных народов. Любой отчет по устойчивому развитию корпораций содержит раздел, посвященный сохранению культуры коренных народов. Наиболее типичными примерами таких проектов являются: «Связь времен», «Сохраняя традиции», «Эстафета поколений», «Живые традиции», «Наследники традиций», «Сохраняя самобытность» (ОАО Сургутнефтегаз 2017; ПАО Газпром нефть 2017; ПАО Лукойл 2017; ПАО НК Роснефть 2017; Сахалин Энерджи 2018).

Компании активно поддерживают проведение традиционных праздников. Самым известным из них является День оленевода. Впервые он стал праздноваться в 1932 г. и назывался День оленя. Тогда целью нового праздника было преодоление старых традиций, продвижение ценностей нового социалистического общества и чествование работников оленеводческих колхозов (Няръяна вындер 1932). В 1987 г. праздник переименован в День оленевода. Многие жители, представители власти и бизнеса этот праздник воспринимают как способ сохранения древних традиций, хотя он имеет короткую историю. Нефтегазовые компании поддерживают восстановление и других традиционных праздников (праздник Кормления духа хозяина моря, праздник оленеводов Курэй, праздник рыболовов Тени Гу). Основные цели проведения мероприятий связаны не только с восстановлением старых обрядов, но и с решением более прикладных задач. Для местных жителей-это возможность привлечь внимание органов власти и бизнеса к своим проблемам, в то время как для компаний- заявить о социальной ответственности с помощью рекламы о спонсорстве этих праздников. Так в официальном сообщении Заксобрания ЯНАО о проведении религиозного обряда «Встреча родов коренных народов» напрямую указывалась ключевая цель мероприятия- улучшение взаимодействия между компаниями, властями и коренными народами:

Обряд решено было провести в целях возрождения обрядово-культовых традиций, восстановления взаимоотношений между жителями Югры и Ямала, власти, нефтяных компаний и коренных народов, сохранения 
традиционных обрядов, самобытной культуры северных этносов. Как отмечает в своем интервью один из руководителей общественной организации коренных народов, цель этого мероприятия-не только дань традициям предков, но и привлечение внимания промышленных компаний к сохранению духовной культуры коренных народов (ФедералПресс 2017).

Другое направление политики сохранения традиционной культуры, финансируемое корпорациями, связано с производством предметов традиционного быта и одежды для домов культуры, краеведческих музеев и фольклорных фестивалей. В некоторых случаях коренные жители уже утратили знания и навыки по их изготовлению, и приходится обращаться к мастерам из других регионов: «Нам извне стараются [помогать], чтобы сохранить природу, самобытность. Нас начинают учить, как это делать» (оленевод-1, деревня Т, ХМАО, 2014). Производство отдельных предметов определяется стремлением сделать их более зрелищными. Например, традиционные костюмы для фестивалей создаются из нетрадиционных тканей более ярких цветов, чтобы привлечь внимание зрителей: «B дни оленеводов у нас сейчас одежда превратилась в стилизованную. Например, малица уменьшилась в размерах. Сейчас мы называем её мини-юбками. Потому, чтоб зрелищно это было со сиены» (местный житель, пос. Т, ХМАО, 2014). Это показывает ориентацию коренных жителей на запросы и внимание со стороны внешних игроков в процессе реконструкции культурных артефактов.

Отдельное внимание уделяется проектам по сохранению национальных языков. Компании финансируют проведение этнографических экспедиций, в ходе которых собираются песни и сказания на национальных языках. На основе собранных материалов издаются сборники сказаний и песен (Санги 2013). Еще одно направление посвящено развитию традиционных промыслов: изготовлению национальной одежды, посуды, игрушек. Для этого проводятся отдельные мастер-классы или организуются регулярные занятия в домах культуры и школах. Основная цель таких занятий декларируется в программах как овладение традиционным знанием (Ассоциация КМНС 2017). В то же время ряд исследователей отмечает, что ключевой характеристикой таких занятий является «фольклоризация» и отсутствие ориентации на их практическое применение (Давыдов 2006). Ученикам показывают наиболее типичные элементы национальной культуры, созданные в прошлом и соответствующие единому унифицированному стандарту.

Фокус на консервации наиболее типичных культурных паттернов связан с представлениями корпоративных менеджеров о культуре коренных народов как неизменяющемся феномене. Несмотря на то что коренные жители активно вовлечены в рыночные отношения и используют в своей жизни современные технологии, это вызывает удивление у менеджеров компаний:

Они уже себя не представляют без «Бурана». А ведь это не традиционный уклад. Традиционный уклад- это оленья упряжка. И никакой дизельной станции. Потому что традиционный уклад-это традиционный 
уклад, как жили твои предки. Там этого, конечно, ничего нет (представитель нефтегазовой компании-2, Сургут, 2014).

Таким образом, корпоративные программы по сохранению культуры коренных народов в большей степени повторяют государственную политику и ориентированы на поддержание того, что считается традиционным. Традиция в зависимости от политического и социального контекста служит инструментом подавления или открывает доступ к новым ресурсам и возможностям. В советское время культуры коренных народов представлялись как отсталые и примитивные. Приверженность традиционному образу жизни рассматривалась как недостаток. Это служило обоснованием репрессивной культурной политики государства в отношении этих народов. В современном мире сохранение традиций стало рассматриваться как ценность и культивироваться международными фондами и организациями. В некоторых случаях мы встречаемся с «переизобретением традиций»- процессом ритуализации определенных практик, опирающихся на апелляцию к историческому прошлому (Hobsbawm, Ranger 1983). При этом «переизобретенные традиции» конструируются исходя из современных потребностей сообщества, а не только служат инструментом сохранения памяти о прошлом (там же). Примерами может считаться реконструкция традиционных праздников. Поддержка традиционных проектов в сфере культуры позволяет корпорациям формировать у местных жителей представление о том, что они не разрушают среду, а наоборот, бережно сохраняют наследие коренных народов. Обращение к традиции используется коренными народами в качестве аргумента в спорах с промышленными компаниями или органами власти при отстаивании своих прав на землю.

\section{Способы распределения средств на проекты в сфере культуры}

Важный аспект культурной политики в регионах связан с инструментами принятия решений в отношении поддержки тех или иных культурных инициатив. Здесь можно выделить два основных механизма: централизованное распределение средств через органы власти и систему грантов, выдаваемых напрямую местным жителям (Tulaeva, Nysten-Haarala 2019; Тулаева, Тысячнюк 2017). В первом случае компании выделяют определенную сумму органам власти, которые принимают решения о поддержке тех или иных культурных проектов и мероприятий. В некоторых случаях представители компаний могут участвовать в выборе направлений, на которые будут потрачены деньги. Подобной стратегии придерживается большинство российских нефтегазовых компаний. Это позволяет наладить отношения с органами местной власти и служит неформальной гарантией присутствия компании в регионе: «Предложение готовит прежде всего 
округ, он говорит: "Вот давайте то-то, то-то сделаем"» (представитель нефтегазовой компании-1, Сургут, ХМАО, 2014). Кроме того, такой подход обосновывается представителями компаний и властей тем, что администрации округа и районов наилучшим образом осведомлены о наиболее важных потребностях местных сообществ.

Тем не менее бывают выбивающиеся из общей практики случаи, в которых решения о поддержке проектов принимаются при участии местных сообществ. Наиболее примечательным является опыт «Сахалинской энергии», которая разработала и внедрила на Сахалине «План содействия КМНС» (Сахалин Энерджи 2016). В его управлении принимают участие представители компании и органов власти, но основные решения о поддержке принимаются представителями коренных жителей.

В целом разница в инструментах принятия решений не приводит к кардинально разным стратегиям в области сохранения и развития культуры коренных народов. Поддержку получают примерно одни и те же мероприятия, которые соответствуют утвердившимся стереотипам и нацелены на «фольклоризацию» культуры.

\section{Заключение}

Доминирующим измерением в конструировании государственной культурной политики в отношении коренных народов является представление о культуре как о традиционном искусстве и фольклоре. Региональные структуры, согласно нормативным документам, поддерживают это направление посредством проведения «традиционных» праздников, конкурсов и фестивалей. В результате мы можем констатировать охранительную стратегию по поддержанию культурного наследия КМНС, маркируемого как «традиционное».

Участие нефтегазовых корпораций в развитии культурной сферы не изменило ситуацию кардинальным образом. Основные проекты связаны не столько с развитием культуры коренных народов и адаптацией местных сообществ к рыночным условиям, сколько с поддержанием условного традиционализма и консервацией имеющихся элементов культуры. Консервация локальной культуры, соответствующей представлениям внешних участников (органы власти, компании, международные организации), сопряжена с международным дискурсом «возрождения и сохранения» и локальными практиками его воплощения. Последние выражаются в создании фольклорных ансамблей, восстановлении ремесел, публикации сказаний и легенд, проведении национальных праздников (Давыдов 2006). Эта политика связана с упрощением и унификацией культуры, созданием единого стандарта, которому должны соответствовать все образцы данной культуры. Как правило, этот стандарт создается наиболее влиятельными игроками (в данном случае, это органы власти и компании). А консервации 
в ряде случаев подлежат элементы культуры коренных народов, созданные в советское время в процессе «окультуривания» и гомогенизации.

Можно выделить несколько причин, способствовавших традиционалистской политике и нейтрализовавших творческую деятельность частных акторов в развитии локальной культуры. Основная причина связана с целями, которые преследуют предприятия, участвуя в культурных программах регионов. Задача корпораций-это не столько развитие и сохранение локальной культуры, сколько минимизация рисков для работы в регионе. Культурные мероприятия должны служить легитимации деятельности нефтегазовых компаний в регионах в глазах местных жителей и уменьшить вероятность конфликтов между ними. Поддержка традиционных проектов в сфере культуры позволяет формировать представление о том, что они не разрушают среду, в которую приходят, а наоборот, бережно сохраняют культурное наследие. Фокус на народной культуре позволяет простроить историческое обоснование, связав современную промышленность с историей здешних мест. Это инструментальное отношение к культуре свойственно как властям, так и корпорациям.

Второй причиной такой культурной политики является сохранение патерналистского отношения к коренным народам. Компании, вслед за государством, воспроизводят патерналистский подход при взаимодействии с коренными жителями. В большинстве случаев корпорации предпочитают взаимодействовать не с местным населением, а с органами власти, передавая им денежные средства на развитие территорий и право самим распоряжаться этими средствами. Те в свою очередь распределяют полученные средства, используя устоявшиеся способы управления. В результате такие программы не способствуют выстраиванию партнерских отношений между разными группами акторов. Даже в тех случаях, когда некоторые нефтегазовые корпорации пытаются привлекать местные сообщества к принятию решений в отношении поддержки социальных и культурных проектов (например, на Сахалине), это не меняет ситуацию существенным образом.

В-третьих, серьезным ограничением в разработке и выборе культурных программ служат стереотипные представления о коренных народах, которыми руководствуются корпорации и власти. Основываясь на стереотипах, компании выстраивают ожидания и запросы в отношении культуры коренного населения. Являясь доминирующими экономическими агентами, они навязывают собственные представления и правила, которым местные жители вынуждены соответствовать. Например, доминирует трактовка культуры коренных народов, как неизменного образа жизни. Подобные убеждения поддерживают традиционализм в реализации культурных программ, что означает консервацию «советского традиционного образа» культуры КМНС. Таким образом, именно частные акторы, как правило, встраиваются в реализуемый региональными властями курс культурной политики. 


\section{Материалы для анализа}

Администрация НАО (2013) Сохранение и развитие коренных малочисленных народов Севера в Ненеиком автономном округе, № 401-п от 11.11.2013.

Ассоциация КМНС (2017) Народная программа «Коренные 2021: Земля. Традиции. Будущеее». Доступно по ссылке: https://clck.ru/PmbFg (дата обращения: 10 августа 2019).

Няръяна вындер (1932) Долой старые праздники! (41): 4.

ОАО Сургутнефтегаз (2017) Годовой отчет. Доступно по ссылке: https://clck.ru/ GnUU6 (дата обращения: 4 августа 2019).

ПАО Газпром нефть (2017) Отчет об устойчивом развитии. Доступно по ссылке: https://clck.ru/PmbKN (дата обращения: 4 августа 2019).

ПАО Лукойл (2017) Отчет о деятельности в области устойчивого развития. Доступно по ссылке: https://clck.ru/GtpWN (дата обращения: 4 августа 2019).

ПАО НК Роснефть (2017) Отчет в области устойчивого развития. Доступно по ссылке: https://clck.ru/PmbM8 (дата обращения: 4 августа 2019).

Правительство НАО (2019) Об оленеводстве в Ненеиком автономном округе. Доступно по ссылке: https://clck.ru/PmbNK (дата обращения: 15 августа 2019).

Правительство РФ (2009) Концепция устойчивого развития коренных малочисленных народов Севера, Сибири и Дальнего Востока Российской Федерации, № 132-р от 04.02.2009.

Правительство РФ (2016) Стратегия государственной культурной политики на период до 2030 года, № 326-р от 29.02.2016.

Правительство ХМАО-Югры (2013) Социально-экономическое развитие коренных малочисленных народов Севера Ханты-Мансийского автономного округа - Югры на 2018-2025 годы и на период до 2030 года, № 398-п от 03.10.2013.

Правительство ЯНАО (2013) Основные направления развития культуры на 20142020 годы № 1122-п от 25.12.2013.

Правительство ЯНАО (2016) Об оленеводстве в Ямало-Ненеиком автономном округе. Доступно по ссылке: https://clck.ru/PmbT8 (дата обращения: 15 сентября 2019).

Президент РФ (2013) Стратегия развития арктической зоны Российской Федерации и обеспечения национальной безопасности на период до 2020 года, № Пр-232 от 08.02.2013.

Санги В. (ред.) (2013) Эпос сахалинских нивхов. М: ИП Смирнова М.А.

Сахалин Энерджи (2016) План содействия развитию коренных малочисленных народов Севера Сахалина. Третий пятилетний план (2016-2020). Доступно по ссылке: https://clck.ru/PmbUX (дата обращения: 10 сентября 2018).

Сахалин Энерджи (2018) Отчет об устойчивом развитии. Доступно по ссылке: https://clck.ru/PmbVQ (дата обращения: 4 августа 2019).

ФедералПресс (2017) Коренные жители Ямала и Югры проведут обряд предков. Доступно по ссылке: https://clck.ru/PmbWq (дата обращения: 10 сентября 2018). 
Федеральный закон (1992) Основы законодательства Российской Федерачии о культуре, № 3612-I от 09.10.1992.

Федеральный закон (1999а) О гарантиях прав коренных малочисленных народов Российской Федерации, № 82-ФЗ от 30.04.1999.

Федеральный закон (1999b) О народных художественных промыслах, № 7-Ф3 от 06.01.1999.

Федеральный закон (2001) О территориях традиционного природопользования коренных малочисленных народов Севера, Сибири и Дальнего Востока Российской Федерации № 49-Ф3 от 07.05.2001.

EBRD (2014) Environment and Social Policy. London: EBRD.

United Nations (2009) Guidelines on Indigenous Peoples' Issues. Доступно по ссылке: https://clck.ru/PmbZi (дата обращения: 20 февраля 2020).

\section{Список источников}

Волков В. (1996) Концепция культурности, 1935-1938: советская цивилизация и повседневность сталинского времени. Соџиологический журнал, (1/2): 204-220.

Давыдов В. (2006) Культурная аутентичность и коренные народы: институциональные процессы и политика идентичности. Журнал социологии и социальной антропологии, 9 (3): 93-109.

Лебина Н. (1999) Повседневная жизнь советского города: Нормы и аномалии. 1920-1930 годbl. СПб.: Летний Сад.

Новикова Н.И. (2013) Коренные народы российского Севера и нефтегазовые компании: преодоление рисков. Арктика: экология и экономика, 11 (3): 102-111.

Тулаева С., Тысячнюк М. (2017) Между нефтью и оленями: о распределении благ между нефтяниками и коренными народами в российской Арктике и Субарктике. Экономическая сочиология, 186 (3): 70-96.

Хестанов Р. (2013) Генезис культурной политики и возникновение массовой культуры в СССР (1917-1953). Сочиология власти, (8): 74-96.

Чуйкина С. (2005) Музеи отечественной истории и литературы XX века в современной России: переработка советского опыта и стратегии кризисного менеджмента. НЛО, (74): 482-505.

Abankina T. (2016) Models for Arts and Culture Financial Support. Journal of US-China Public Administration, 13 (3): 173-180.

Dubois V. (2013) Cultural Policy Regimes in Western Europe. Доступно по ссылке: https://clck.ru/Pmbe5 (дата обращения: 15 октября 2019).

Grant B. (1995) In the Soviet House of Culture: A Century of Perestroikas. Princeton: Princeton University Press.

Gurova O. (2020) Patriotism as Creative (Counter-)Conduct of Russian Fashion Designers, Consumer Culture Theory. Research in Consumer Behavior, (20): 151-168. 
Hadley S., Gray C. (2017) Hyperinstrumentalism and Cultural Policy: Means to an End or an End to Meaning? Cultural Trends, 26 (2):95-106.

Hobsbawm E., Ranger T. (1983) The Invention of Traditions. Cambridge: Cambridge University Press.

McGuigan J. (2004) Rethinking Cultural Policy. Berkshire: Open University Press.

Menger P.- M. (2010) Cultural Policies in Europe. From a State to a City-Centered Perspective on Cultural Generativity. In: National Graduate Institute for Policy Studies (GRIPS), Policy Research Center. Discussion Paper: 10-28.

Mulcahy K. V. (2006) Cultural Policy: Definitions and Theoretical Approaches. The Journal of Arts Management, Law, and Society, 35 (4):319-330.

Novikova N., Wilson E. (2013) The Sakhalin 2 Project Grievance Mechanism, Russia. In: E. Wilson, E. Blackmore (eds.) Dispute or dialogue? Community perspectives on company-led grievance mechanisms, (5-7): 84-109.

Rodgers D. (2015) The Depth of Russia. Oil, Power and Culture after Socialism. Ithaca: Cornell University Press.

Stammler F., Wilson E. (2006) Dialogue for Development: An Exploration of Relations between Oil and Gas Companies, Communities and the State. Sibirica, 5 (2): 1-42.

Tulaeva S., Nysten-Haarala S. (2019) Resource Allocation in Oil-Dependent Communities: Oil Rent and Benefit Sharing Arrangements. Resources, 8 (86): 1-20. 
Natalia Zhidkova, Svetlana Tulaeva

\title{
CULTURAL POLICY IN RUSSIA'S REGIONS: THE STATE, CORPORATIONS AND INDIGENOUS PEOPLE
}

\begin{abstract}
This article analyses the role of corporations in the production of cultural policy in Russia's regions. It examines different approaches to understanding state cultural policy, as well as what functions can be performed by non-state actors. The main focus of the article is on corporate projects aimed at preserving and developing indigenous culture in the regions of the North and the Far East. The regions selected for the study are characterised by a high degree of socio-economic dependence on extractive corporations. Using a qualitative methodology, research is based on semi-structured interviews, an analysis of documents, and observation. Despite the innovative potential of the private actors described in the theoretical literature, corporate projects in Russia's regions tend to duplicate state policy in cultural policy and reproduce a traditionalist approach. Adherence to tradition is considered not only to be a way of increasing the symbolic significance of culture, but also as a tool for implementing tasks. Support for traditional cultural projects allows corporations to leave the impression that they do not destroy the environment they come to, but, on the contrary, carefully preserve the legacy of the past. Indigenous people can also successfully appeal to tradition in disputes with oil companies or authorities. At the same time, on closer examination, it turns out that the traditional culture of indigenous peoples, that persists, was created in Soviet times during the process of 'domestication' and homogenization. The main factors that have neutralised the creative potential of non-state actors are related to a pragmatic understanding of culture by both state and non-state actors, the preservation of paternalistic relations between companies and local communities, the presence of certain stereotypes about traditional culture.
\end{abstract}

Key words: cultural policy, oil and gas corporations, indigenous people

DOI: 10.17323/727-0634-2020-18-3-429-444

\section{References}

Abankina T. (2016) Models for Arts and Culture Financial Support. Journal of US-China Public Administration, 13 (3): 173-180.

Chuykina S. (2005) Muzei otechestvennoy istorii i literatury XX veka v sovremennoy Rossii: pererabotka sovetskogo opyta i strategii krizisnogo menedzhmenta [Museums of Russian History and Literature of the Twentieth Century in Modern Russia: Processing of the Soviet Experience and Crisis Management Strategy]. Novoe literaturnoe obozrenie [New Literature Review], (74): 482-505.

Natalia Zhidkova- Cand. Sci. (Pol.), Associate Professor, North-Western Institute of Management, Russian Academy of National Economy and Public Administration, Saint Petersburg, Russia. Email: zhidkova.ng@gmail.com

Svetlana Tulaeva-Cand. Sci. (Soc.), PhD in Legislative studies, Associate Professor, North-Western Institute of Management, Russian Academy of National Economy and Public Administration, Saint Petersburg, Russia. Email: svett07@mail.ru 
Davydov V. (2006) Kul'turnaya autentichnost' i korennye narody: institutsional'nye protsessy i politika identichnosti [Cultural Authenticity and Indigenous Peoples: Institutional Processes and Identity Politics]. Zhurnal sotsiologii i sotsial'noy antropologii [Journal of Sociology and Social Anthropology], 9 (3): 93-109.

Dubois V. (2013) Cultural Policy Regimes in Western Europe. Available at: https://clck.ru/Pmbe5 (accessed 15 October 2019).

Hadley S., Gray C. (2017) Hyperinstrumentalism and Cultural Policy: Means to an End or an End to Meaning? Cultural Trends, 26 (2): 95-106.

Hobsbawm E., Ranger T. (1983) The Invention of Traditions. Cambridge: Cambridge University Press.

Grant B. (1995) In the Soviet House of Culture: A Century of Perestroikas. Princeton: Princeton University Press.

Gurova O. (2020) Patriotism as Creative (Counter-)Conduct of Russian Fashion Designers, Consumer Culture Theory. Research in Consumer Behavior, (20): 151-168.

Lebina N. (1999) Povsednevnaya zhizn'sovetskogo goroda: Normy i anomalii. 1920-1930 gody. [Daily Life of the Soviet City: Norms and Anomalies. The Years 1920-1930]. St. Petersburg.: Summer Garden.

Khestanov R. (2013) Genezis kul'turnoy politiki i vozniknovenie massovoy kul'tury v SSSR (1917-1953) [Genesis of Cultural Policy and the Emergence of Mass Culture in the USSR (19171953)]. Sotsiologiya vlasti [Sociology of power], (8): 74-96.

McGuigan J. (2004) Rethinking Cultural Policy. Berkshire: Open University Press.

Menger P.- M. (2010) Cultural Policies in Europe. From a State to a City-Centered Perspective on Cultural Generativity. In: National Graduate Institute for Policy Studies (GRIPS), Policy Research Center. Discussion Paper: 10-28.

Mulcahy K.V. (2006) Cultural Policy: Definitions and Theoretical Approaches. The Journal of Arts Management, Law, and Society, 35 (4):319-330.

Novikova N.I. (2013) Korennye narody rossiyskogo Severa i neftegazovye kompanii: preodolenie riskov [The Indigenous Peoples of the Russian North and Oil and Gas Companies: Overcoming Risks]. Arktika: ekologiya i ekonomika. [Arctic: Ecology and Economics], 11 (3): 102-111.

Novikova N., Wilson E. (2013) The Sakhalin 2 Project Grievance Mechanism, Russia. In: E. Wilson, E. Blackmore (eds.) Dispute or Dialogue? Community Perspectives on Company-led Grievance Mechanisms, (5-7): 84-109.

Rodgers D. (2015) The Depth of Russia. Oil, Power and Culture after Socialism. Ithaca: Cornell University Press.

Stammler F., Wilson E. (2006) Dialogue for Development: An Exploration of Relations between Oil and Gas Companies, Communities and the State. Sibirica, 5 (2): 1-42.

Tulaeva S., Tysnyuk M. (2017) Mezhdu neft'yu i olenyami: o raspredelenii blag mezhdu neftyanikami i korennymi narodami v rossiyskoy Arktike i Subarktike [Between Oil and Deer: On the Distribution of Benefits Between Oil Workers and Indigenous Peoples in the Russian Arctic and Subarctic]. Ekonomicheskaya sotsiologiya [Economic sociology], 18b (3): 70-96.

Tulaeva S., Nysten-Haarala S. (2019) Resource Allocation in Oil-Dependent Communities: Oil Rent and Benefit Sharing Arrangements. Resources, 8 (86): 1-20.

Volkov V. (1996) Kontseptsiya kul'turnosti, 1935-1938: sovetskaya tsivilizatsiya i povsednevnost' stalinskogo vremeni [The Concept of Culture, 1935-1938: Soviet Civilization and Everyday Life of Stalin's Time]. Sotsiologicheskiy zhurnal [Sociological Journal], (1/2):204-220. 